\title{
Social and Cultural Euphemism in Saudi Arabic: a Semantic, a Pragmatic and a Sociolinguistic Analysis
}

\author{
Bakri Al-Azzam (Corresponding author) \\ Department of English Language and Literature, The Hashemite University, P.O. Box 330127, Zarqa 13133, Jordan \\ E-mail: bakriazzm2013@gmail.com \\ Mohammad Al-Ahaydib \\ College of Language and Translation, Imam Mohammed Ibn Saud Islamic University, Riyadh, Kingdom of Saudi Arabia \\ E-mail: miahaydib@yahoo.com \\ Norah Alkhowaiter \\ College of Language and Translation, Imam Mohammed Ibn Saud Islamic University, Riyadh, Kingdom of Saudi Arabia \\ E-mail: norahkh9@gmail.com \\ Husam Al-Momani \\ Department of English Language and Literature, The Hashemite University, P.O. Box 330127, Zarqa 13133, Jordan \\ E-mail: HusamS@hu.edu.jo
}

Doi:10.7575/aiac.alls.v.8n.2p.64

Received: 04/02/2017

URL: http://dx.doi.org/10.7575/aiac.alls.v.8n.2p.64

Accepted: 19/03/2017

\begin{abstract}
This paper explores the universal linguistic phenomenon of the social and cultural euphemism in Saudi Arabic. It aims at improving the understanding of other cultures' readers of the Saudi culture, concerning uses of euphemism, and simultaneously showing how some linguistic expressions are essentially products of social and cultural pressures. To examine this notion, the study analyzes and classifies examples of the most frequently used Saudi Arabic euphemism, based on various topics. The study shows that the social and cultural factors are very influential in expressing euphemism. It also reveals a clear and a huge shift in the use of euphemism in the Saudi culture, where Saudis did not apply euphemisms frequently in the past, as they are applying these days. Because of the new development of the country's economy, openness, interfaith dialogue, cultural communication, new lifestyles have emerged and called for more prestigious linguistic behavior. It is hoped that the study would uncover why there are certain sensitive situations where euphemism is needed, such as those of religion, social circumstances, and death situations.
\end{abstract}

Keywords: euphemism, taboos, Saudi Arabia, culture, semantics

\section{Introduction}

In human interactions, language is used to communicate and express meanings. Nevertheless, it is sometimes used to avoid talking about certain matters that are socially perceived as taboo, which Wardhaugh (2010), defines as follows: "Taboo is the prohibition in any society of behavior to be harmful to its members in that it would cause them anxiety, embarrassment, or shame. It is an extremely strong politeness constraint. Consequently, as far as language is concerned, certain things are not to be said, or they are talked about in very roundabout ways" (p. 249). The shortest of these "roundabout ways" are euphemisms. Wardhaugh refers to euphemism as the "dressing up" of language (p. 251). The unpleasantness of certain topics, such as death, sickness, or criminality, is "neutralized" or "disguised" by euphemistic expressions (p. 251).

In Saudi Arabia, people frequently use euphemism and noticeably more than before. Decades ago, Saudis were dwellers of the desert, and the harsh conditions made them direct in their speech and actions. However, due to technological revolution, a new lifestyle and culture emerged. Politeness and formality have become more important than ever, and the delicate use of words, to avoid harm or displeasure, has shown sensitivity to certain topics. Manners, certain occupations, body functions, death, and fatal diseases are now inspiring much more formal and polite speech.This study aims at investigating the cultural and social influence on the use of euphemism in Saudi Arabia; it attempts to reveal that the cultural and social factors have heavily assisted in creating situations and settings, where the use of euphemism is found necessary. Not only this, it tries to show that the various situations of euphemism use in the Saudi Arabia reflect the clear structure of the values, beliefs, religion, customs, and the change of view toward certain circumstances, where euphemism was one day not very frequent in the society. This, in turn, reveals that the Saudis were not euphemistically expressing situations in the past, as they were direct in their expression. 


\section{Euphemism and language}

Etymologically, the English term "euphemism," which was developed in the late 16th century, comes from the Greek "euphemismos," with the root "phemi" meaning "speaking" and the prefix "eu" meaning "good" or "well." Hence, the entire word means "speaking well" (Euphemism, 2016). Neaman and Silver (1985) claim that the linguistic phenomenon of euphemism flourished first in religious discourse. However, Epstein (1985) contends: "In the beginning was the word. There followed, at an undetermined but one assumes decent interval, private, harsh, and dirty words. Invention here being the mother of necessity, the need for euphemism arose" (p. 56).

Many researchers and linguists have provided definitions of euphemism. Most definitions consider euphemism to be a type of "amelioration," which primarily focuses on substituting socially acceptable expressions for others that cannot be expressed explicitly (Al-Shamali, 1997, p. 3). Willis and Klammer (1981) define it as "a mild or roundabout word or expression used instead of a more direct word or expression to make one's language delicate and inoffensive even to a squeamish person" (p. 193). Similarly, Hudson (2000) defines it as "the extension of ordinary words and phrases to express unpleasant and embarrassing ideas" (p. 261). More recently, in 2009, Gomez explains it as "the cognitive process of conceptualization of a forbidden reality, which, manifested in discourse through the use of linguistic mechanisms, ... enables the speaker to attenuate a certain forbidden concept or reality" (p. 736). From these definitions, it can be stated that euphemisms have a great semantic effect on language, and a strong link with society and culture. They employ semantic strategies not to avoid the problematic topic, but to permit an alternative approach to it.

All cultures share the universal phenomenon of Euphemism. According to Brown and Levinson (1987) ample evidence "indicates that euphemisms are a universal feature of language usage" (p. 216). For instance, in Standard Arabic, euphemisms are applied on a large scale. Because Standard Arabic is the language of the Quran, it is characterized by beauty, eloquence, and rhetoric. For example, the word $\mid$ |وليتلطف is located in the exact middle of the Quran as shown in the verse (وليتلطف ولا يشعرن بكم احدا...), (lit. to walk gently that nobody would observe). It refers to the call for men to soften their language and attitude. According to Al-Hamad and Salman (2013), "The location draws an interesting image of the importance of euphemism and social decency. Just like the word |ولينلطف which is surrounded with thousands of tokens on both sides, individuals can also be surrounded with other society members and win their acceptance by morals and soft language" (p. 190). The Quran also sets a practical example by euphemizing many harsh topics, such as death, sex, genitals, excretory functions, and disabilities. Although Arabs do not use Standard Arabic in everyday interactions, euphemisms are commonly applied in various Arabic dialects and in various situations.

Euphemism in different languages may differ due to the influence of beliefs, customs, traditions, and religions. Some philosophers proclaim languages as reflections of cultures and the true record of people's history. Accordingly, the speakers' efforts to cover up certain words or expressions forbidden in public can be a cultural reflection in language (Allan \&Burridge, 2006, p. 12). This paper, explores euphemisms in the Saudi culture to point out the social aspects of the Saudi community, and reveal the various factors behind using euphemisms in certain situations. It can be stated here that euphemism is culturally based, and the utterance of euphemistic expression is made accordingly. In a comparative study of Chinese and Western euphemism, Guo (2010) maintains that because of the variations of geographical and economic factors, Chinese and western cultures are diversified. People with different cultural backgrounds would not deal with the same issue in exactly the same way, which will definitely be reflected in the features of their respective languages.

As far as Arabic euphemism is concerned, many studies have handled this semantic issue in different Arab countries. For example, some Jordanian studies have investigated the use of euphemism in Jordanian Arabic such as Elyyan (1994), who examines the frequency of euphemisms used in situations of death and sickness; Al-Shamali (1997) who explores euphemisms as used in the Jordan Valley dialect; and Farghal (1995) who studies the nature of euphemism in Arabic in general and Jordanian Arabic in particular; Farghal argues that Arabic euphemisms break one or more of the maxims of conversation. Other studies have been conducted on other Arabic dialects that have considered euphemism. They have made a comparison between Arabic and English Euphemism. To exemplify, Rabab'ah and Alqarni (2012) conduct a numeric survey to compare the frequency of euphemism between Saudis and British in topics concerning death, body parts, and lying.

The discussion or the analysis of this linguistic phenomenon is based on the selection of examples that represent different topics of euphemism in Saudi Arabia. These examples show the Saudi social culture; they reflect the Saudis' viewpoints toward these various topics, and cover areas of religion, body parts and functions, description of human, sexuality, woman, diseases, occupations and social positions, and other offensive topics.

\section{Discussion}

Euphemism in Saudi Arabia covers different areas or topics, which may not be treated similarly in other cultures, even those that share the Saudi culture in language, religion, traditions and beliefs. This linguistic feature includes among other things, religion, social beliefs, and politics. In societies, where political freedom is so narrow, euphemism can be clearly observed. According to Crespo-Fernandez (2014), euphemism serves different purposes in the corpus of political language consulted: avoidance of discrimination to disadvantaged groups, concern for people's sensitivity, polite criticism and mitigation-even concealment-of unsettling topics. But whatever its communicative function, politicians adopt euphemism as a means of self-promotion within a more general politeness strategy of positive selfpresentation. 
As for the outline of the discussion and analysis of the selected sample of the linguistic phenomenon, and for purely organizational reasons, the euphemistic examples are classified into several areas. Each type is discussed separately in order to clearly and considerably investigate how this semantic issue is used or practiced in the Saudi Arabic.

\subsection{Euphemism related to religion}

Islam is the religion of the Kingdom of Saudi Arabia. Most Saudis can be described as religiously oriented and conservative. Thus, euphemisms are considerably influenced by Islam. In many situations and social settings, Saudis generally euphemize by using religious reference, as shown below:

اجني (in the Name of Allah), for (ghosts). In Islam, Jinns are creatures such as human beings, and Muslims strongly hold this belief. This is clearly observed in the verse (وما خلقت الإنس و الجن الا ليعبدون) (lit. I have created man and Jinns just to worship Me). Another idea that should be considered about those creatures is that people cannot see or observe them, though they could observe people as clearly noticed in the verse (يرونكم من حيث لا ترونهم), (lit. they see you from where you cannot see them). Saudis avoid uttering the names of ghosts directly, because it is said that when one utters "them," they immediately appear. Therefore, saying \بسم الله \(in the Name of Allah) instead of (ghosts) is considered euphemistic in Saudi Arabic and is believed as a way of protection from their appearance.

2 الصدقة/ charity. This is clear in the verse (اللهقسمة|الذين في امو الهم حق معلوم للسائل و المحروم), (giving of God) instead ofit. those in whose property there is a prescribed right for the needy and poor). By nature, needy people are sensitive when they are given even their due or rights, and for such a reason the giving or the due is euphemistically uttered or said as قسمة الله (giving of Allah). Saudis use this expression to show humbleness and respect the feelings of the poor, by stating that this is their right from God.

ايتوضأ|يجد (wash or ablution). In Islam, Muslims observe five prayers a day. Before observing each prayer, Muslims must have the state of ablution. Breaking the wash can be due to many factors such as breaking winds, responding to the call of nature, or practicing sexual intercourse. Before each prayer, Muslims wash their face, hands, and feet. The word $\backslash$ yujaddid $\backslash$ is used to indicate the renewal of their purity before every prayer, because it refers to purifying oneself from one's inner bodily functions, and is related to the use of the toilet, which is far in meaning from purifying for prayer.

4 The question | تكمل دينك؟ $\square$ (When will you complete your religion?) is used instead of asking, "When will you decide to get married?" In Islam, marriage is a sunnah, recommended but not obligatory. This is clear in the Hadith \ن استطاع منكم الباءة فليتزوج ال (lit. whoever of you is able to marry should marry). However, because it is highly praised in Islam, Muslims conceive of it as stepping ahead in their religion. Therefore, Saudis use the religious term instead of directly asking "When will you decide to get married?",which seems vulgar and indicates intrusion into personal matters. This indirectness of interrogation softens down any anger or wrath of the addressee and motivates him to answer the question in the right manner. Socially and culturally, marriage is a private matter, and that is why

is frequently used in Saudi Arabia to inquire about one's intention or plan for marriage.

\subsection{Euphemisms related to body parts and functions}

As Al-Shamali (1997) notes, bodily functions are among the most severe taboos in many cultures. Accordingly, people refer to such functions euphemistically, to avoid any violation of politeness of cultural norms. The following examples are illustrative of euphemisms related to body parts and functions in Saudi Arabic:

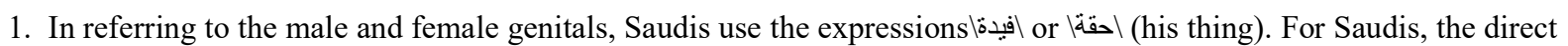
reference to male and female genitals is considered very offensive and impolite, even in informal situations. Therefore, when they refer to these genitals, they use "thing" to avoid any embarrassment or offense.

2. In referring to the female menstrual cycle, Saudis use the expression الدورة| (the cycle or period) or العادة) (the habit), instead of stating the direct term الحيضل| الحيض, though the Qur'an is clear and direct in the reference as clear in the verse

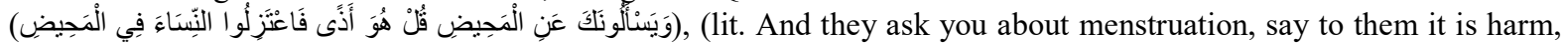
and so do not approach women in this state). Doing so avoids embarrassing a woman in a social gathering especially in the presence of foreign women or male relatives. Saudis also use terms such as العا لها صلاة \ال العذاة (she has no prayer) (the excuse), since women are licensed not to perform prayers during their period.

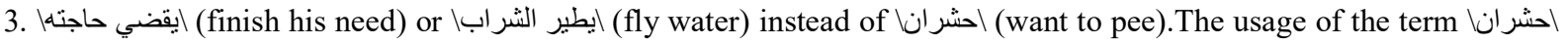
in informal situations is not taboo or impolite, but arouses disgust. On the other hand, in formal situations, it is very important to use the euphemistic expressions such as finish his need, or fly water, since any violation in such matters is impolite.

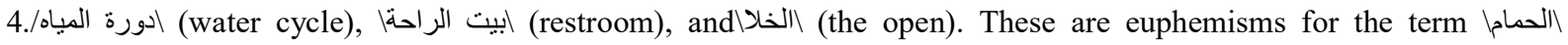
(bathroom). They are used to prevent disgust or offensiveness to others. The term \دورة (water cycle) is the standard use of the word in Arabic and is now used on a wide scale among Saudis in both their formal and informal speech. The euphemism|الخلا \(the open) is also used in Standard Arabic and is common among elderly Saudi people. It is called "the open" because people before industrialization used to go to the open desert to attend to their bodies' needs, or reply to the call of nature.

\subsection{Euphemisms related to human descriptions}

Huang (2005) suggests that one of the main functions of euphemisms is to express politeness. Thus, when speaking about someone's body type or deformity, people try to avoid insensitivity or harshness, using euphemisms to save others' faces. Following are examples that illustrate this view in Saudi Arabia: 


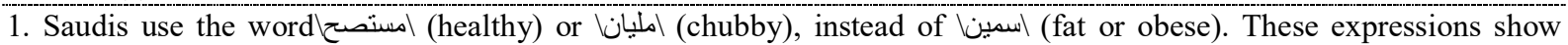
respect. They indicate that a person is full of body and in good health, instead of saying a person is fat.

2. Saudis use the expression \خلق الله حسن (God's creation is good) to describe an unpleasant or an ugly person.

3. Saudis use the word اخال| to denote to a black man, because the word \بدال|wich was used in the past, is considered very degrading and insulting and carries the connotations of a slave. The expression $\backslash$ \ند is not acceptable nowadays in Saudi Arabia, just as the word "nigger" is insulting and unacceptable in the West. The new euphemism الخال| does not have a clear origin, but commonly speaking, it is taken from the name of the black facial beauty mark (which is called ' اخال|dot' in Saudi Arabic) to give the description of a person a touch of beauty, as the beauty mark does.

4. Saudis use اكريمعينه (he has got an honorable eye), instead of (one-eyed). Since the word "one-eyed" may hurt one's feelings, this euphemism is used to show that, although a person may not see out of one eye, the other eye is generous in sight. This expression is thus much more accepted among Saudis.

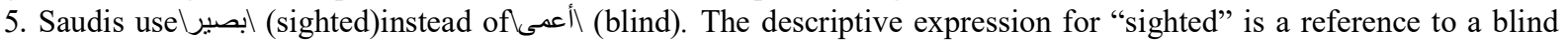
person. It indicates the opposite of the truth, to produce a more positive effect on the referent or to figuratively exhibit the person's keen insight and good judgment.

6. Saudis use الشوية عقليتة أو بسيط (narrow-minded), instead of امجنون (mad) to refer to a mentally disabled person; they use this jargon term or the euphemism\إبسطة عقليته, to avoid being directly judgmental or hurting the feelings of the person's family.

\subsection{Euphemisms related to sexuality}

Due to the religious and conservative nature of Saudis, it is considered rude and vulgar to speak about sexual intercourse in public. Thus, Saudis use general expressions whenever they need to speak about the subject.

1. The expression اينام مع (sleep with) is used as euphemism خق indicator of sexual intercourse. This expression is usually used in informal conversation.

2. To refer to this sexual topic publicly and in formal situations, Saudis use several euphemisms used in the Quran. For example, they use the term (لامستم, which means touched, serves as a euphemized expression for sexual intercourse (AlHamad, 2013, p. 203). Other Quranic euphemisms include the expression يقرب|(come to) or (come near to), which areclearly understood as "have sex with" (Al-Hamad, 2013, p. 203).

3.5 Euphemisms related to reference to women

Al-Hamad (2013) argues that, contrary to the typical misconception, women occupy a very special position in Arab societies. He says: "Arabs have long expressed their respect and appreciation of women through the use of some honorifics, instead of calling their actual names" (p. 205). On the other hand, some Arab females believe that using a term other than their actual names might indicate that referring to their names directly is considered taboo. For one reason or another, Saudis use many euphemistic expressions to refer to their wives, daughters, and mothers.

1. The expression (كريمته| (his dignified) refers to one's daughter. This expression used to be very common, especially in wedding invitations. However, in recent years, the term has started to decline. Saudi fathers have become more excited about choosing new and outstanding names for their daughters; they are eager to announce them in public.

2. Referring to one's wife as الأهل (the family) is another general common expression in Saudi Arabia. It is also used to refer to one's sisters. This expression is still very common among Saudi men, young and elderly.

3. Some Saudi men do not mention their mothers' first names publicly. Therefore, they call their mothers by their older son's name in public - for example,|الم المدال (mother of Ahmad). Another way is to call their mothers by their last name, adding the female suffix "يه." If her last name is الخهالدية| (Al-Khalid ) people may call her (الخالد, (Al-Khaldiyah). This type of expression is mostly used with elderly women.

\subsection{Euphemisms related to death and fatal diseases}

According to Allan and Burridge (2000), death is painful and fearful to many people, and the euphemizing of expressions for death is universal. The most common euphemism for death in Standard Arabic is iاتوفى a synonym for "passed away." However, Saudis use many others, as illustrated below:

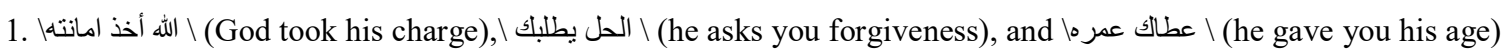

These euphemisms appear in both formal and informal contexts of speech, instead of the expression (ماتركرات (died). Their main purpose is to prevent shock to others when delivering this type of news, especially to a relative.

2. Expressions like أحسن الله عز الك| (may God gratify your condolences) and الله الكرك| (may God glorify your reward) are condolence utterances. According to Rabab'ah and Al-Qarni (2012), "Such utterances might reflect religious tendencies, which serve to belittle the fear aroused by the event of death" (p. 736).

3. The expressions الخيبث |الثين الخيثل, meaning the "malignant" or bad, are euphemisms for cancer. Saudis avoid shocking or saddening listeners by describing cancer rather than naming it. When they mention this disease, Saudis usually utter a certain invocation to ask for refuge in God from it: or الله يكفينا شرها (lit. may Allah save use from its evil or harm).

4. Saudis use اعليه قل صحة| (not in full health) when a person is sick. Saudis do not directly say the person is sick or ill.

3.7 Euphemisms related to reference to occupations and social positions

According to Wardhaugh (2010), euphemisms "also allow us to give labels to unpleasant tasks and jobs in an attempt to make them sound almost attractive. Euphemism is endemic in our society: the glorification of the commonplace and the elevation of the trivial" (p. 251). This use of euphemism is very common in Saudi Arabia:

1. The expression |مطربة| (singer) refers to a female singer in weddings, instead of the old expression (drummer), which they find degrading. This euphemized expression may be a result of social developments regarding class, since 
|طقاقة| is used in lower-class communities, while upper classes prefer the euphemism |مطربة|, to give it a more prestigious description.

2. The expression \عامل نظافة (عامل بلدية| (cleanness worker) is used instead of the term \بال| (trash man). The expression (municipality worker) is a new euphemism that avoids degrading or humiliating a worker, referring to him working in the municipality of cleaning, is a much more delicate reference.

3. The expression حارس (guardian) refers to a person who secures the gates of schools or buildings usually occupied by females. This euphemism is also fairly new. Saudis use it to give the person a feeling of importance and power in his

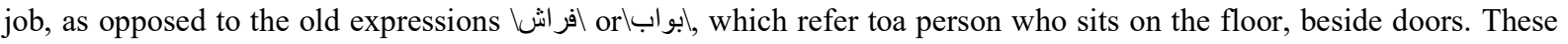
terms are considered offensive and are related to poverty and need.

4. The expression خالة|خ (aunt) refers to the cleaning lady in schools. This euphemism is used to express respect and appreciation to these women, who are usually older than the schoolgirls and teachers.

5. The expression المرة| (the woman) is an expression used instead of (الشغالة) (house maid). This euphemistic expression is very common among elderly Saudis who want to avoid indicating a house worker by a name that refers to her job, which they think is offensive. Therefore, they choose to refer to her generally as "the woman."

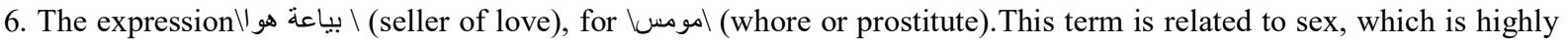
euphemized in Saudi Arabia. The term امومس is very direct and considered offensive. To avoid directness, sex is referred to by the warmer term "love." In fact, this expression comes from Standard Arabic and is now used on a wide scale between Saudis in their formal and informal speech.

7. The expression اجارة| (neighbor) is not used here as "neighbor"; rather, it is used among Saudis, informally, to refer to the second wife of the husband. Thus, instead of calling her $|\overrightarrow{\mid l}|$, a word taken from "harm," they use this euphemism to avoid the sensitiveness and negative connotations of the direct term, especially in the presence of other women.

8. The expression اخالة| (aunt) is a euphemism for "mother-in-law" in Saudi Arabia, to indicate that the husband's mother is like an aunt in her care. Also, this avoids the negative perception of a mother-in-law as evil or devious to her daughter-in-law.

\subsection{Euphemisms related to reference to other offensive topics}

In addition to the above situations, where euphemism is used to avoid any assumed offense, Saudis have other social and cultural settings and events where euphemism is clearly observed. To mention but a few, the following examples illustrate some of these situations:

1. The expression الكرها ل ما هضمتة| (I could not digest him), indicates hatred toward someone else. Instead of saying hate...), Saudis use this expression to avoid directly showing their negative feelings towards a person.

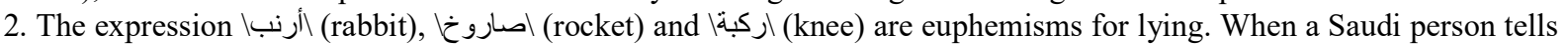
lies in an informal company or gathering, Saudis use any of these expressions to indicate he is lying, but do not state it directly; they utter this euphemism to notify or acknowledge the speaker that they are aware of his lies. These understated expressions are humorous and less harsh, and only used in informal situations to joke with friends or relatives. In formal situations, Saudis choose to trivialize lies. For example, the expression لمع معول (incredible!!) is a way of making the lie less important and passing it off.

3. The expression $\mid{ }^{\prime}$ (good?) is used among Saudis when a person intrudes during their speech or involves himself or herself where s/he should not. This euphemism is an alternative to the rude and direct "This is none of your business!" It is an indirect hint to the intruding person of his misbehavior.

4. The expression اكذاك و ذال (this and that) is a mysterious euphemism used in Saudi Arabia to refer to secrets or the unsaid, mainly to things that may be considered taboo, obscene, or vulgar. This expression is used, informally, in the very conservative Saudi community or in the presence of children.

\section{Conclusion}

The paper has investigated the semantic and pragmatic functions of euphemism in spoken Arabic in Saudi Arabia. The examples have revealed that Saudis tend to euphemize many topics, such as human descriptions, genitals, bodily functions, women, occupations, sicknesses, and death, because of offense resulting from the direct use of speech in such events and situations.. The study has pointed out that Saudis replace the words relating to these topics with less direct expressions to avoid offense or embarrassment. In addition, the selected examples have revealed that Saudis use euphemisms in both formal and informal occasions, and have reflected many aspects of Saudi Arabic and social culture.

In addition, the study has concluded that the wide spread of euphemisms in recent years shows the linguistic development of the Saudi dialect due to economic growth, educational development, global interaction among societies, and new linguistic behaviors that fit the new Saudi culture.

More importantly, the study has revealed that Saudis frequently refer to religion in their euphemized expressions, when referring to topics such as death, sickness, and human descriptions, especially in difficult situations. A final conclusion is observed when euphemized expressions are used to refer to women, where Saudi men used to be proud when their daughters', mothers', or relatives' names are spoken in public. For example, King Abdul-Aziz, the first monarch of Saudi Arabia, used to call himself the "brother of Norah" أخو نورة| This recent linguistic attitude of some Saudis needs further investigation, to explain the shift in referring to women's names publicly. 


\section{References}

Al-Hamad, M., \& Salman, A. M. (2013). The translatability of euphemism in the holy Quran. European Scientific Journal,9 (2), 190-214.

Allan, K. \& Burridge, K. (2000). Euphemism and dysphemism: language used as shield and weapon. New York: Replica Books.

Allan, K. \& Burridge, K. (2006).Forbidden words: taboo and the censoring of language. Cambridge: Cambridge University Press.

Al-Shamali, F. (1997). Facets of euphemism in Jordan valley dialect (Unpublished master's thesis).Yarmouk University, Irbid, Jordan.

Brown, P. \& Levinson, S. (1987). Politeness: some universals in language usage. Cambridge: Cambridge University Press.

Elyyan, F. (1994). Variation in the use of euphemisms in Jordanian Arabic.(Unpublished master's thesis).Yarmouk University, Irbid, Jordan.

Epstein, J. (1985). Sex and euphemism. In D. J. Enright (Ed.),Fair of speech: The use of euphemism. Oxford: Oxford University Press.

Euphemism. (2016). In OxfordDictionaries.com. $\quad$ Retrieved $\quad$ November $7, \quad 2016 \quad$ from https://en.oxforddictionaries.com/definition/euphemism

Farghal, M. (1995). Euphemism in Arabic: A Gricean interpretation. Anthropological Linguistics, 37 (3), $366-378$.

Crespo-Fernandez, E (2014) Euphemism and Political Discourse in the British Regional Press, vol.40, no, 1, Brno Studies in English: Universitas Masarykiana Brunensis.

Gómez, M. C. (2009). Towards a new approach to the linguistic definition of euphemism. Language Sciences, 31 (6), 725-739.

Guo, Q (2010) Cultural Differences in Chinese and English Euphemisms, in Cross-Cultural Communication, vol.6, no. 4, pp 135-144, www.cscanada.net: Canada.

Huang, Y. (2005). “A Brief Study of the Origin, Forms and Change of English Euphemisms."US-China Foreign Language, 3, 46-48.

Hudson, R. A. (1996). Sociolinguistics. Cambridge: Cambridge University Press.

Neaman, J. S. \& Silver, C. G. (1985).Kind words: A thesaurus of euphemisms. New York: McGraw-Hill.

Rabab'ah, G. \& Al-Qarni, A. M. (2012).Euphemism in Saudi Arabic and British English. Journal of Pragmatics, 44 (1), 730-743.

Wardhaugh, R. (2010) . An introduction to sociolinguistics. Oxford: Wiley-Blackwell.

Willis, H. \&Klammer, E. (1981).A brief handbook of English. New York: Rinehart and Winston. 